\title{
Glandular papilloma of the lung with malignant transformation
}

\author{
Woo Jung Sung \\ Department of Pathology, Catholic University of Daegu, School of Medicine, Daegu, Korea
}

\begin{abstract}
Glandular papilloma of the lung is one of three histologic types of solitary endobronchial papillomas. It is known as an uncommon benign neoplasm. No malignant glandular papillomas have been reported. Herein, the first case of granular papilloma with malignant transformation is reported. A 74-year-old man with huge right lung mass extended upper and lower lobe was admitted to the hospital complaining of progressive cough and dyspnea. An open lung biopsy was performed. Microscopically, the tumor showed papillary growth pattern with thick fibrovascular cores. The stroma of the fibrovascular cores shown the infiltration of lymphoplasmacytic cells and proliferation of capillaries. The epithelial cells surrounding the papillary fronds were cilliated columnar cells with focal cellar atypia, and frequent mitoses. Suspicious pleural invasion foci were identified. The Ki-67 labeling index was about $24.3 \%$ and p53 labeling index was about $31.7 \%$. Glandular papilloma is known as a benign neoplasm, which is lack of atypia and mitosis. In present case, there were several indications of malignant transformation, such as cellular atypia, frequent mitosis, architectural distortion, and pleural invasion. Pathologists must be aware that glandular papilloma can have a changes of malignant transformation. Further studies about disease behavior and molecular characteristics are needed.
\end{abstract}

Keywords: Glandular papilloma; Pulmonary papilloma; Malignant transformation; Lung; Pulmonary

\section{INTRODUCTION}

Glandular papilloma of the lung is one of three histologic types of solitary endobronchial papillomas. It is known as an uncommon neoplasm and most glandular papilloma arise from central lobar or segmental bronchi [1-3]. Few reports of pulmonary papillomas described arising in peripheral endobroncholar lesions. Glandular papilloma is a benign papillary growing tumor comprised of a thick fibrovascular core and papillomatous fronds lined by cillicated or non-cillicated columnar epithelium. There have been no reports of the malignant trans-

Received: October 19, 2017, Revised: October 26, 2017 Accepted: October 30, 2017

Corresponding Author: Woo Jung Sung, Department of Pathology, Catholic University of Daegu, School of Medicine, 33 Duryugongwon-ro 17-gil, Nam-gu, Daegu 42472, Korea

Tel: +82-53-650-4159, Fax: +82-53-650-3456

E-mail:wjsung@cu.ac.kr formations of glandular papillomas, unlike squamous cell papilloma and mixed squamous cell and glandular papilloma, which have the potential to be malignant [4]. Herein, the first case of granular papilloma with malignant transformation is reported to the best of our knowledge.

\section{CASE}

A 74-year-old man was admitted to a hospital complaining of progressive cough and dyspnea for 6 months. On chest $\mathrm{X}$-ray, huge right upper lobe mass invading right lower lobe was identified (Fig. 1A). He had been taking medication for angina pectoris. He was an ex-smoker, who had 20 pack years smoking history. It was noted that three years prior, a $3.5 \mathrm{~cm}$ sized right upper lobe mass revealed on chest X-ray, but the patient had refused further evaluation (Fig. 1B). A bronchoscopic examination showed the mass was an endobroncheal polypoid mass on the right bronchus. On chest computed

Copyright $($ C) 2017 Yeungnam University College of Medicine

This is an Open Access article distributed under the terms of the Creative Commons Attribution Non-Commercial License (http://creativecommons.org/licenses/by-nc/4.0/) which permits unrestricted non-commercial use, distribution, and reproduction in any medium, provided the original work is properly cited. 

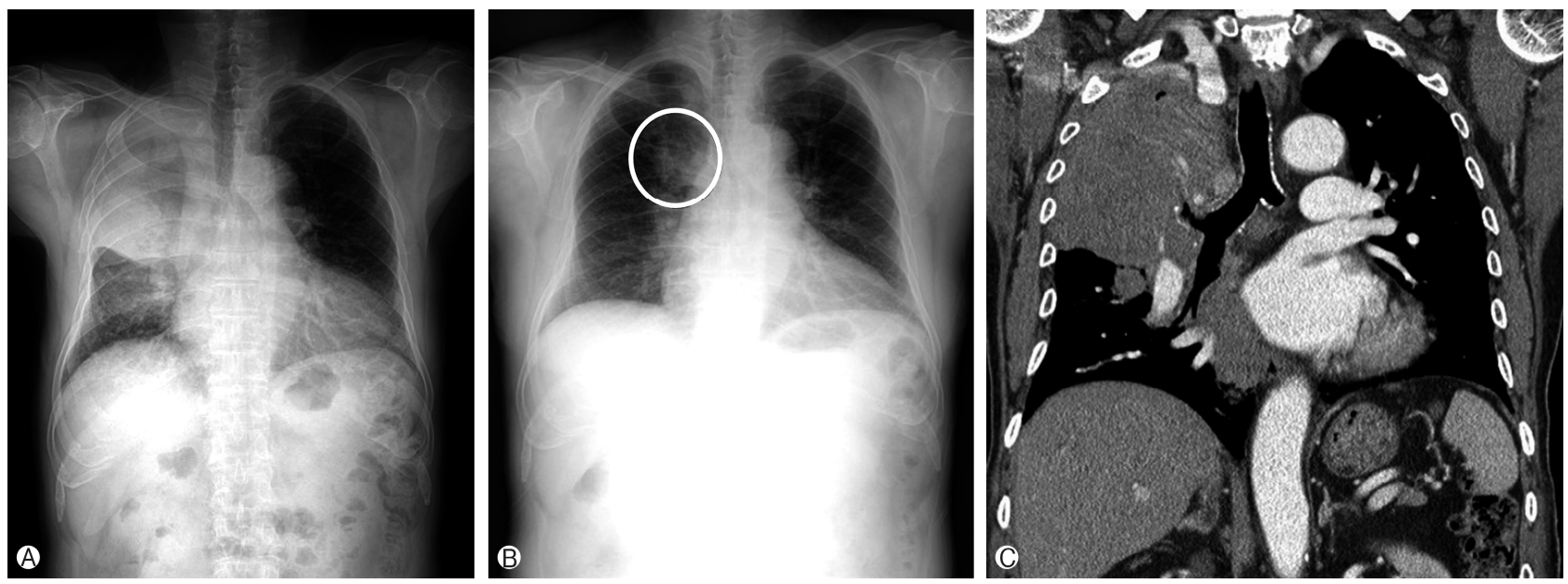

Fig. 1. Radiologic images of the right lung mass. The chest X-ray reveals a large mass at right upper lobe invading right lower lobe (A). On chest X-ray of 3 years prior, a $3.5 \mathrm{~cm}$ sized right upper lobe mass was identified (circle) (B). About $8.5 \mathrm{~cm}$-sized right upper and lower lobe mass is visible in a chest computer tomography $(\mathrm{C})$.

tomography, about $8.5 \mathrm{~cm}$-sized huge lung mass was identified in right upper and lower lobes (Fig. 1C). The mass involved mediastinum, right upper lobar bronchus, and superior segment of right lower lobe. Suspicious nodal involvement was noted at the right paratracheal and subcarinal areas. An open lung biopsy was performed on right middle lobe, because the bronchoscopic and percutaneous needle biopsy were insufficient for diagnosis.

The submitted lung tissue was two pieces, measuring $3.5 \times$ $2.5 \mathrm{~cm}$ and $2.2 \times 1.3 \mathrm{~cm}$ in dimension. Microscopically, the tumor had numerous thick fibrovascular cores with papillary growing fronds (Fig. 2A). Infiltration of lymphoplasmacytic inflammatory cells, predominantly plasma cells, and capillary proliferation were present in stroma of the thick fibrovascular cores. The stroma also had focal granulomatous and edematous areas. The epithelial cells surrounding the papillary fronds were cilliated columnar cells with focal cellar atypia. The epithelial cells had grown single or pseudostratified layers, and clear cytoplasm was frequently observed (Fig. 2B). The sizes of the nuclei were relatively uniform, but some had increased in size; moreover some nucleoli had appeared. The nuclei were aligned at regular intervals on the bottom of a single layered epithelial cells. However the nuclei moved to the upper portions of the cytoplasms in areas of nuclear atypia. Focal complex epithelial architectures and mitotic figures (three in each high-powered field in the most active area) were present (Fig. 2C). Pleural invasion was identified in separately submitted specimen (Fig. 2D). The epithelial cells were positive for thyroid transcription factor-1, Napsin A, cytokeratin 7 (CK7), and negative for p63 at immunohistochemistry. CK7 helped to recognize the growing structure of epithelial cells and demonstrated the lesions suspected of invasion (Fig. 3A, 3B). Ki-67 and p53 were positive for some nuclei of epithelial cells. The labeling index of Ki-67 and p53, analyzed using the program GenASIs HiPath, was about 24.3\% and 31.7\%, respectively (Fig. 3C, 3D). Epidermal growth factor receptor and KRAS mutation tests using PNAclamp Mutation Detection Kit (PANAGENE Inc., Daejeon, Korea) were negative.

The patient received chemotherapy with a combination of cisplatin and pemetrexed for 6 cycles, but there was no remarkable change in the size of the mass. The patient came to the emergency room with severe dyspnea. He showed septic condition and was treated with antibiotics. The condition did not improved, and he expired 10 months after discovering the deteriorated chest X-ray.

\section{DISCUSSION}

Solitary pulmonary papillomas are known as rare benign endobronchial neoplasms that are usually derived from bronchial surface epitheliums [1-3]. They are accounted for only $0.38 \%$ of all lung tumors [5] and approximately $7 \%$ of all benign epithelial and mesenchymal lung tumors [6]. At bronchoscopy, they appear as endobronchial masses, which cause narrowing of the airway lumen approximately $40 \%$ to $60 \%$ 
of its normal diameter $[3,4]$. Solitary pulmonary papillomas can be divided into three categories according to the epithelial cell histology: squamous cell papilloma, glandular papilloma, and mixed squamous cell and glandular papilloma (mixed papilloma) [2]. Squamous cell papilloma is the most common subtype of pulmonary papilloma [7].

Glandular papilloma is apparently rare, as only 20 cases have been reported in English literature since the first case had been reported in 1954 [4,5]. Glandular papilloma make up about $20 \%$ of solitary pulmonary papillomas [4]. It appears predominantly in the central lobar or segmental bronchus $[8,9]$, but few peripheral lesions also reported [4,10]. It arises on the mucosal surface, and range in size from 0.7 to $4 \mathrm{~cm}$ [2]. Common symptoms include coughing, wheezing, and hemoptysis, and it is sometimes discovered incidentally [4].

Microscopically, glandular papilloma has fibrovascular cores lined with papillomatous growing pseudostratified or single layer of ciliated or non-ciliated columnar cells. Cuboi- dal or goblet cells can be admixed [2]. The columnar cells have eosinophilic cytoplasms and regular round nuclei. Cytologic or architectural atypia is not prominent [10], and mitosis and necrosis do not occur [10-12]. The fibrovascular cores often contain the infiltration of plasma cells.

The World Health Organization classifies solitary pulmonary papillomas as benign epithelial tumors of the lung, because they are rarely malignant. The few malignant carcinoma cases have been reported and usually related to favorable prognoses [2-4]. Tryfon et al. [4] reported the clinical and histologic data of 101 patients with solitary respiratory papillomas, including 32 cases of their own data and 69 cases from literature review. Malignant transformation occurred in $11(10.9 \%)$ of the pooled 101 cases of solitary pulmonary papillomas [4]. According to their report, 7 (10.8\%) out of 65 patients of squamous papilloma, and 4 (25\%) out of 16 patients of mixed papilloma developed malignant transformation [4]. No cases developed malignant transformation
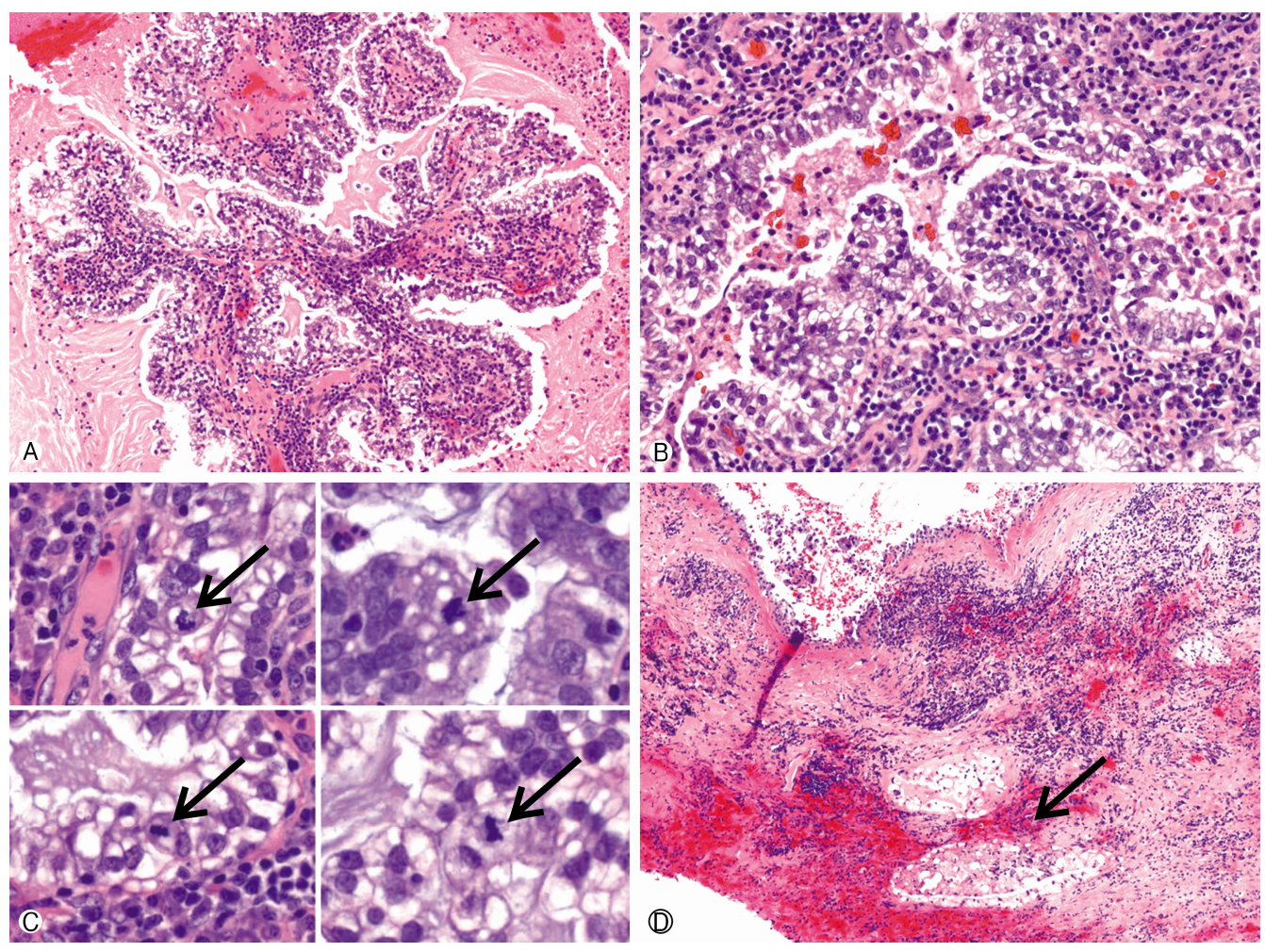

Fig. 2. Microscopic findings of the mass. On low-powered field, the tumor shows papillary growing fronds with thick fibrovascular cores (A, H\&E stain, $\times 40$ ). The stroma of fibrovascular cores has massive infiltration of lymphoplasmacytic cells (peripheral area) and the surrounded columnar epithelial cells are growing pseudostratified (lower) or single layer (upper) (B, H\&E stain, $\times 200)$. The tumor cells have clear cytoplasm and mitotic figures (arrows) (C, H\&E stain, $\times 400$ ). Pleural invasion is identified at separately submitted specimen (arrow) (D, H\&E stain, $\times 40)$. 
from glandular papilloma [4]. All patients with malignant transformation of their own data were smokers [4].

In present case, luminal growing thick abundant fibrovascular core with papillary growing fronds lined by cilliated columnar cells was matched with histology of glandular papilloma. As aforementioned, there was several evidence of malignant transformation, such as cellular atypia, frequent mitotic figures, architectural distortions, stromal-invaded epithelial cells, and pleural invasion. Mitotic figures have not been reported in previous reported glandular papilloma cases. The epithelial cells surrounded thick fibrovascular cores showed inverted growing in multiple areas. The outer contours of the some entrapped glands showed sharp irrupted features, which could be found well by CK7 immunohistochemistry.

In several reports, benign glandular papilloma was misconstrued as to have a malignant change $[7,11,13]$. Peripheral bronchiolar papillomas spread along alveolar walls and display an appearance similar to peripheral adenocarcinomas of the bronchioloalveolar or papillary type [7]. For differential diagnosis, it is noteworthy that endobronchiolar papillomatous fronds are constantly present and spread along the alveo- lar walls is limited in alveoli adjacent to peripheral papillomas [7]. Accompanied fibroblastic organization or cellular atypia could be presented as secondary changes to bronchiolar obstruction or inflammation [11]. Features which aid in differentiation are the absence of significant cytologic atypia, hyperchromasia, mitoses, and necrosis in the papilloma [13].

In this case, the characteristic papillary growth with thick fibrovascular core that can be seen with glandular papilloma showed throughout the open biopsy specimen and pleural biopsy. Generally, lung adenocarcinoma is frequently displayed a mixed growth pattern and this feature can be seen even in small biopsies. However, this case showed the characteristic histologic features of glandular papilloma, which are different from the papillary growth pattern of adenocarcinoma. There were no remarkable other usual growth patterns of lung adenocarcinoma throughout the specimen. For these reasons, it is believed that it is appropriate to diagnose as glandular papilloma with malignant transformation, not simply adenocarcinoma.

A few reports have mentioned Ki-67 and p53 expression of solitary pulmonary papillomas. Miyoshi et al. [14] noted

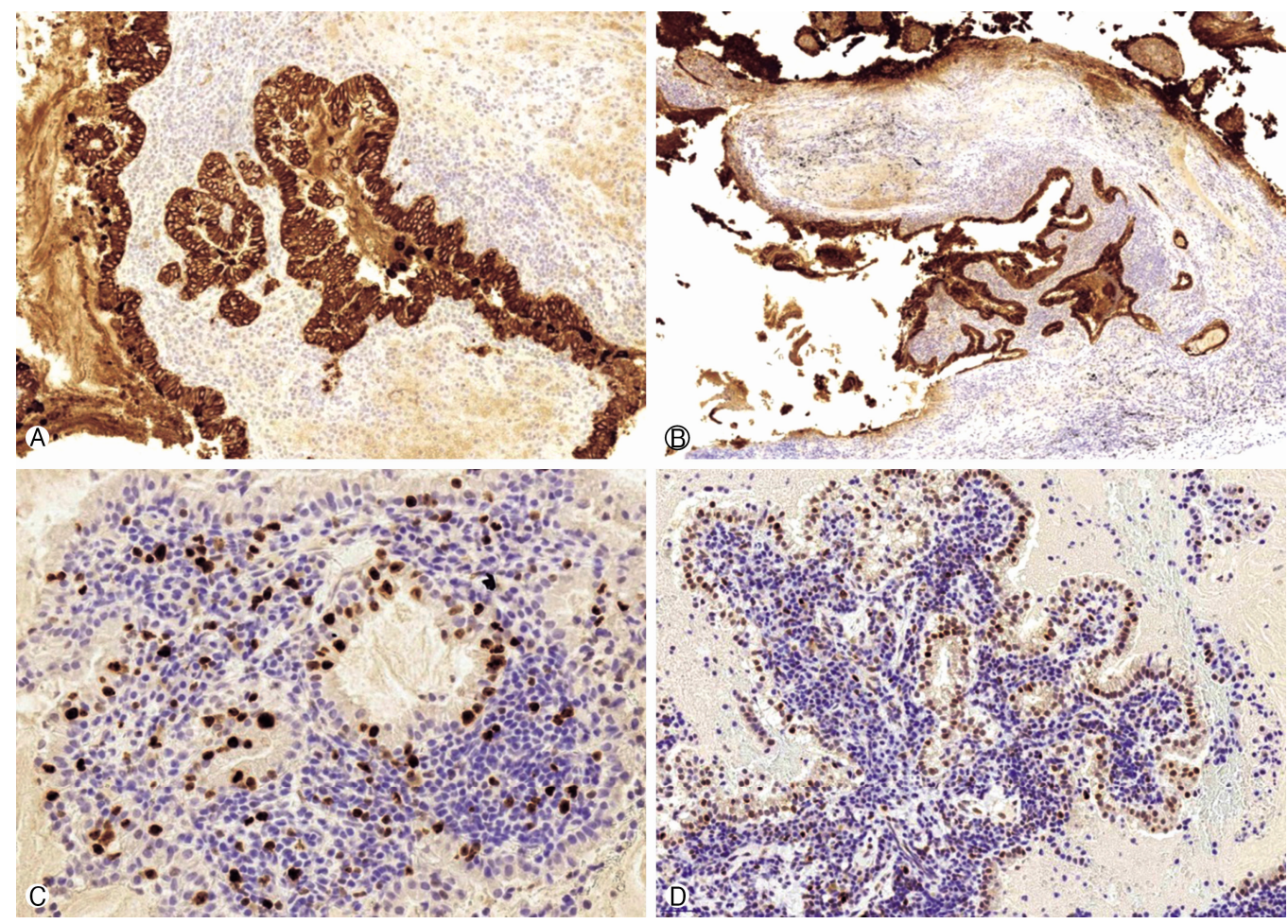

Fig. 3. Immunohistochemistry. Cytokeratin 7 helps to recognize the growing structures of epithelial cells $(A$ and $B)$. Invasion foci are demonstrated in papillary frond $(A, \times 40)$ and pleura $(B, \times 20)$. The Ki-67 labeling index was about $24.3 \%(\mathrm{C}, \times 200)$, and the p53 labeling index was about $31.7 \%(\mathrm{D}, \times 100)$. 
a small number of positive cells for $\mathrm{p} 53$ and Ki-67 were scattered in mixed squamous cell and glandular papilloma. Aida et al. [10] reported the Ki-67 labeling index ranged from 2.3\% to $12.0 \%$ in their three cases of glandular papilloma. The maximum value, $12.0 \%$, was seen in the bronchiolar region of one case and the peripheral regions showed low values of $4.7 \%, 5.7 \%$, and $2.3 \%$, respectively [10]. The p53 labeling index was less than $10 \%$ in each of the three cases [10].

In present case, the highest labeling index of Ki-67 was $24.3 \%$, and $\mathrm{p} 53$ was $31.7 \%$. The labeling index of Ki-67 and $\mathrm{p} 53$ were higher than that of previous reported cases in literature. The Ki-67 expression was higher in places with complex architecture and pseudostratified epithelium than in places with single layered epithelium without atypia, whereas p53 expression was evenly distributed.

We reported the first case of glandular papilloma with malignant transformation. There are several evidences of malignant transformation, such as cellular atypia, frequent mitosis, complex architecture, pleural invasion and high Ki-67 and p53 labeling index. Pathologists should carefully consider the features of suggested malignancy in glandular papilloma. Further studies of the disease behaviors and molecular characteristics, especially compared to traditional adenocarcinoma, are needed.

\section{ACKNOWLEDGEMENT}

This work was supported by research grants from Daegu Catholic University in 2012.

\section{CONFLICT OF INTEREST}

No potential conflict of interest relevant to this article was reported.

\section{ORCID}

Woo Jung Sung, https://orcid.org/0000-0001-9510-3763

\section{REFERENCES}

1. Basheda S, Gephardt GN, Stoller JK. Columnar papilloma of the bronchus. Case report and literature review. Am Rev Respir Dis 1991;144:1400-2.

2. Flieder DB, Koss MN, Nicholson A, Sesterhenn IA, Petras RE, Travis WD. Solitary pulmonary papillomas in adults: a clinicopathologic and in situ hybridization study of 14 cases combined with 27 cases in the literature. Am J Surg Pathol 1998;22:1328-42.

3. Spencer H, Dail DH, Arneaud J. Non-invasive bronchial epithelial papillary tumors. Cancer 1980;45:1486-97.

4. Tryfon S, Dramba V, Zoglopitis F, Iakovidis D, Sakkas L, Kontakiotis T, et al. Solitary papillomas of the lower airways: epidemiological, clinical, and therapeutic data during a 22-year period and review of the literature. J Thorac Oncol 2012;7: 643-8.

5. Ashmore PG. Papilloma of the bronchus: case report. J Thorac Surg 1954;27:293-4.

6. Popper HH, Wirnsberger G, Jüttner-Smolle FM, Pongratz MG, Sommersgutter M. The predictive value of human papilloma virus (HPV) typing in the prognosis of bronchial squamous cell papillomas. Histopathology 1992;21:323-30.

7. Kaseda K, Horio H, Harada M, Hishima T. Solitary glandular papilloma of the peripheral lung: a report of two cases. World J Surg Oncol 2014;12:149.

8. Maxwell RJ, Gibbons JR, O'Hara MD. Solitary squamous papilloma of the bronchus. Thorax 1985;40:68-71.

9. Inamura K, Kumasaka T, Furuta R, Shimada K, Hiyama N, Furuhata Y, et al. Mixed squamous cell and glandular papilloma of the lung: a case study and literature review. Pathol Int 2011;61:252-8.

10. Aida S, Ohara I, Shimazaki H, Dai Y, Ogata S, Ozeki Y, et al. Solitary peripheral ciliated glandular papillomas of the lung: a report of 3 cases. Am J Surg Pathol 2008;32:1489-94.

11. Feng AN, Wu HY, Zhou Q, Sun Q, Fan XS, Zhang YF, et al. Solitary endobronchial papillomas with false impression of malignant transformation: report of two cases and review of the literature. Int J Clin Exp Pathol 2015;8:8607-12.

12. Suzuki S, Goto T, Emoto K, Hayashi Y. Rapidly growing glandular papilloma associated with mucus production: a case report. World J Surg Oncol 2014;12:160.

13. Emerson LL, Layfield LJ. Solitary peripheral pulmonary papilloma evaluation on frozen section: a potential pitfall for the pathologist. Pathol Res Pract 2012;208:726-9.

14. Miyoshi R, Menju T, Yoshizawa A, Date H. Expression of p16 (Ink4a) in mixed squamous cell and glandular papilloma of the lung. Pathol Int 2017;67:306-10. 